\title{
Method for Cloning In Vivo Targets of the Egr-1 Transcription Factor
}

BioTechniques 29:162-169 (July 2000)

\section{Ian de Belle, Dan Mercola ${ }^{1}$ and Eileen D. Adamson}

The Burnham Institute, La Jolla, ${ }^{1}$ Sidney Kimmel Cancer Center, San Diego, CA, USA

\section{INTRODUCTION}

Egr-1 is an immediate early growth response gene induced in response to serum stimulation of quiescent or growing cells. The alternate names for Egr-1 reflect the mode of its discovery. We first reported the cloning of the Egr-1 gene in fibroblasts and its role in development and in neuronal activity and differentiation (16). Other names are Zif268 (2), indicating its zinc finger DNA binding motif; Krox24 (1), showing its relation to the Krüppel family of homeobox transcription factors; NGFIA (14), because of its induction in PC12 cells by nerve growth factor; and TIS8 (12), because it is a gene induced by phorbol ester tumor promoters. Egr1 is also the most responsive (mRNA induced within $5 \mathrm{~min}$, protein level maximal at $60 \mathrm{~min}$ ) of the stress-activated genes. Egr-1 is induced by radiation at all wavelengths, all tested growth factors, calcium ions, reactive oxygen species, heavy metals, depolarization and stretch among other stimuli. Its actions are partly governed by the levels achieved, stability and state of phosphorylation. Egr-1 protein is generally short-lived with a half-life of $90 \mathrm{~min}$, but its expression can be much extended after stress and certain other stimuli that lead to its phosphorylation (6).

The Egr-1 gene family codes for transcription factors that bind to GCrich regions in gene promoters. There are several members with similar structural features, but only the zinc finger domain has high homology among family members. The DNA consensus binding sequence is GCGG/TGGGCG, and it occurs in the promoters of several growth-related genes including Egr1 itself, WT1 (related to Egr-1), EGF receptor, PDGF-A, PDGF-B, FGF-2, Bcl-2, p53, TGF $\beta 1$, IGF-II, IGF-IR and a number of extracellular matrix genes. A notable feature of the GC-rich binding site for Egr-1 is that it occurs most frequently in the proximal promoter regions of many growth-related genes, especially those that do not have TATA or CAAT boxes.

One set of genes regulated by Egr-1 endows a tumor suppressor function, and another set endows a survival response to damaging irradiation. Another important function of Egr-1 concerns the differentiation of many cell types. The mechanism for a change in cellular responses caused by Egr-1 would be clarified if we knew what new promoters Egr-1 protein binds to affect the activities. This paper describes and tests such a method by applying a stimulus of UV-C irradiation to determine what new Egr-1 target genes are bound by Egr-1 in HT1080 human fibrosarcoma cells. The cross-linking of proteins to 
DNA was achieved with formaldehyde previously $(5,15)$. The method is termed direct in vivo Egr-1 target (DIVET) cloning. The method may be applied to capture the target genes of any transcription factor for which there is a specific immunoprecipitating antibody.

\section{MATERIALS AND METHODS}

\section{Cells and Culture Conditions}

The human fibrosarcoma HT1080 cell clone, H4, was kindly provided by Dr. S. Frisch (The Burnham Institute). H4 cells stably expressing Egr-1, E9 cells, have been previously described (9). Cells were cultured in DMEM containing $10 \% \mathrm{FBS}$ and maintained in a $5 \%-\mathrm{CO}_{2}$ atmosphere at $37^{\circ} \mathrm{C}$.

\section{Chemical Cross-Linking and Chromatin Isolation}

Formaldehyde-induced cross-linking and chromatin isolation was performed as previously described $(3,11)$. An outline of the procedure is shown as a flow diagram in Figure 1. The optimal time of exposure of $\mathrm{H} 4$ and E9 cells to formaldehyde was determined by pilot experiments to be $1-2 \mathrm{~h}$. This length of exposure was found to give and was based on a method described

the best yield of Egr-1 capture from the cross-linked chromatin. Cross-linking was performed on approximately $1 \times$ $10^{7}$ attached cells in $15-\mathrm{cm}$ dishes. Chromatin, purified by urea gradient centrifugation at $50000 \times g$ for $16 \mathrm{~h}$, was stored at $-80^{\circ} \mathrm{C}$. Before immunoprecipitation, 30-60 $\mu \mathrm{g}$ DNA in chromatin were digested overnight at $37^{\circ} \mathrm{C}$ with $60 \mathrm{U}$ EcoRI.

\section{Antibodies and Immunoprecipitation}

An affinity-purified rabbit polyclonal antibody (8) raised against amino acids 27-318 was used for both immunoprecipitation of and Western analysis for Egr-1. The antiserum was affinity-purified over a column of recombinant Egr-1 coupled to CNBr-activated Sepharose ${ }^{\circledR}$ beads (Sigma, St. Louis, MO, USA) .

For immunoprecipitation, 30-60 $\mu \mathrm{g}$ cross-linked and EcoRI-digested chromatin were brought to a volume of 1 $\mathrm{mL}$ in RIPA buffer to which $1 \mu \mathrm{g}$ affinity-purified anti-Egr-1 antibody was added together with $40 \mu \mathrm{L} 50 \%$ suspension of protein A-Sepharose beads. Samples were rotated overnight at $4^{\circ} \mathrm{C}$, and the bead-captured immunecomplexes were washed four times with RIPA buffer. Samples were then washed with TE buffer [10 $\mathrm{mM}$ Tris

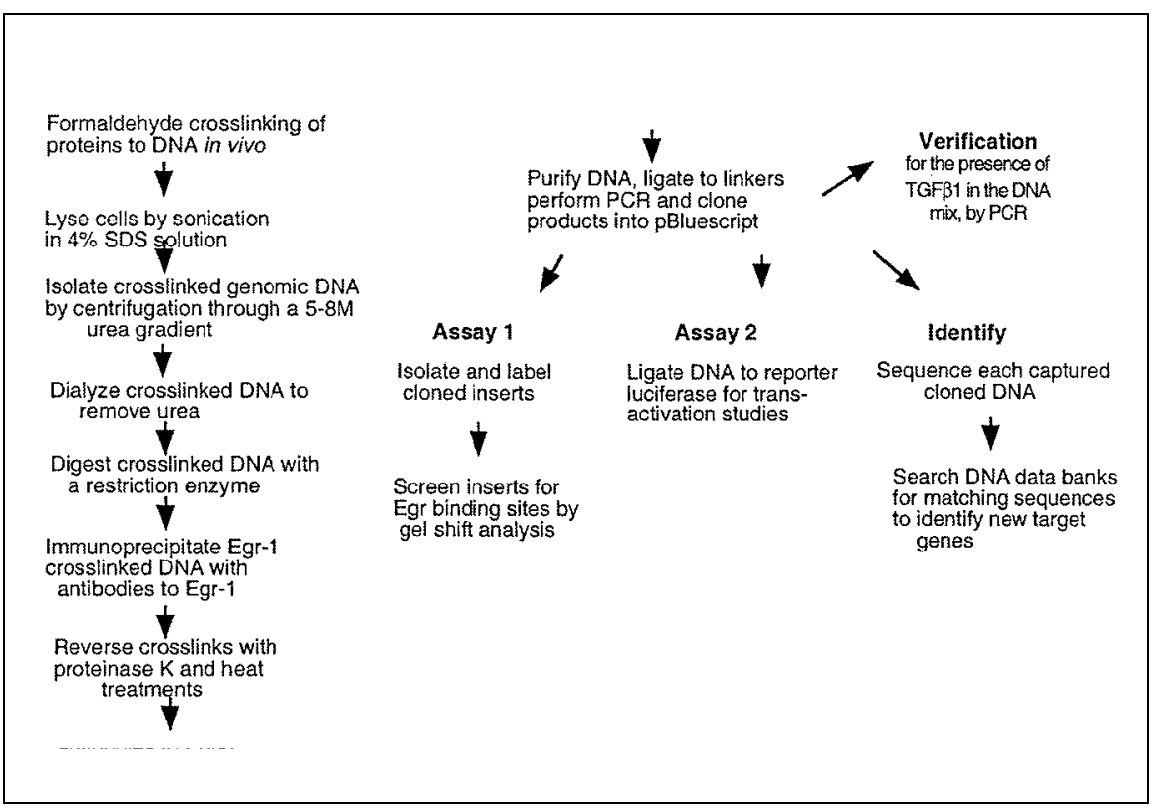

Figure 1. Flowchart to illustrate the early steps of the DIVET cloning procedure.
(pH 8.0) and $1 \mathrm{mM}$ EDTA] and divided into two equal aliquots.

For Western analysis, one aliquot was washed with $10 \mathrm{mM}$ Tris ( $\mathrm{pH} 7.5$ ), $2 \mathrm{mM} \mathrm{MgCl}$, then resuspended in 100 $\mu \mathrm{L}$ of the same buffer with $10 \mathrm{U}$ DNase I (Promega, Madison, WI, USA) and incubated at $37^{\circ} \mathrm{C}$ for $10 \mathrm{~min}$. The samples were then boiled in SDS sample buffer for $10 \mathrm{~min}$ and analyzed by $7.5 \%$ SDSPAGE. Western analysis was performed using the same anti-Egr-1 affinity-purified antibody at a 1:1000 dilution.

For DNA recovery from the second aliquot, cross-links were reversed with heat and proteinase $\mathrm{K}$ (Promega) digestion and DNA purified as previously described (3). Using both proteinase $\mathrm{K}$ digestion and heat treatment has been shown to achieve total reversal of cross-linking, which yields completely protein-free DNA (15).

\section{Linker Ligation and PCR Amplification of Captured DNA}

The purified DNA following crosslink reversal was redigested with $20 \mathrm{U}$ EcoRI at $37^{\circ} \mathrm{C}$ for $2 \mathrm{~h}$ to ensure all ends were compatible with the linkers. The digested DNA was ligated to EcoRI linkers consisting of the following oligonucleotides: 5'-AATTCGAAGCTTGGATCCGAGCAG-3' and 5'-CTGCTCGGATCCAAGCTTCG-3'. Following linker ligation at $16^{\circ} \mathrm{C}$ overnight, the ligated DNA was subjected to PCR amplification.

PCR amplification of the linker-ligated DNA was performed using the 20mer oligonucleotide from the linker ligation as the PCR primer and Pfu DNA polymerase (Stratagene, La Jolla, CA, USA), using buffer conditions supplied by the manufacturer. PCR cycling parameters were as follows: $95^{\circ} \mathrm{C}$ for $45 \mathrm{~s}$, $65^{\circ} \mathrm{C}$ for $30 \mathrm{~s}$ and $72^{\circ} \mathrm{C}$ for $5 \mathrm{~min}$. The number of cycles was determined empirically so that few or no PCR products were visible in the control samples consisting of Egr immunoprecipitates from $\mathrm{H} 4$ cells (Figure 3, lanes 1 and 2). The number of cycles performed was typically 20-30. PCR products were purified by agarose gel electrophoresis and QIAquick ${ }^{\mathrm{TM}}$ gel extraction (Qiagen, Valencia, CA, USA). Linkers were removed by EcoRI digestion, and products were ligated in EcoRI-digested 
pBluescript ${ }^{\circledR}$ (Stratagene). XL2B cells (Stratagene) were transformed with the ligated products, and the individual bacterial colonies were isolated for characterization.

\section{Gel Shift Assay}

The inserts from individual colonies were isolated by EcoRI digestion and labeled for use as probes in a gel shift assay by fill-in synthesis using a Klenow fragment in the presence of $\left[{ }^{32} \mathrm{P}\right]$-dATP. Probes were purified by electrophoresis through a $6 \%$ acrylamide gel, elution in $10 \mathrm{mM}$ Tris $(\mathrm{pH}$ $8.0), 50 \mathrm{mM} \mathrm{NaCl}$ and $1 \mathrm{mM}$ EDTA and then passed through an Elutip ${ }^{\circledR}$-d minicolumn (Schleicher \& Schuell, Keene, NH, USA). The gel shift assay was performed as previously described (7), using recombinant glutathione-S-transferase (GST)-Egr-1.

For gel shift competition, Egr-1 was allowed to bind to the probe for $15 \mathrm{~min}$ at room temperature, and then a 50-fold molar excess of unlabeled competitor oligonucleotide was added and samples incubated for a further $15 \mathrm{~min}$. The wild-type Egr-1 binding sequence used as a specific competitor consisted of the following oligonucleotides: 5'-GATCACTCGCGGGGGCGAGGA- $3^{\prime}$ and 5'-TGAGCGCCCCCGCTCCTCTTAG-3'. For a mutant Egr-1 binding site competitor, the following oligonucleotides were used: 5'-GATCACTCAC-

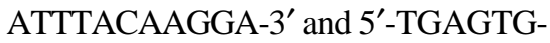
TAAATGTTCCTCTAG-3'.

\section{Luciferase Reporter Assay}

Luciferase reporter plasmids were constructed by ligating the Egr-1-captured DNA sequences into $\mathrm{p} \Delta 56$ fos-Luciferase (a kind gift from Dr. C. Hauser, The Burnham Institute), which contains a c-fos minimal promoter upstream of the luciferase reporter gene. The reporter construct was transfected into $\mathrm{H} 4$ cells in the presence or absence of a cytomegalovirus (CMV)-Egr-1 expression vector by LIPOFECTAMINETM transfection (Life Technologies, Rockville, MD, USA). Forty-eight hours after transfection, cells were collected, lysed in $100 \mathrm{mM} \mathrm{KPO}{ }_{4}$ buffer ( $\mathrm{pH}$ 7.8) containing $0.2 \%$ Triton ${ }^{\circledR} \mathrm{X}-100$ and $1 \mathrm{mM}$ dithiothreitol. The cell lysate was then assayed for luciferase activity in the presence of $10 \mathrm{mM}$ ATP, $15 \mathrm{mM}$ $\mathrm{MgCl}_{2}$ and $0.1 \mathrm{mM}$ luciferin substrate (Analytical Luminescence Laboratory, San Diego, CA, USA). Luciferase activity was measured in an EG\&G Berthold microlumat LB96P luminometer (PE Biosystems, Foster City, CA, USA).

\section{PCR Amplification of the TGF $\beta 1$ Promoter}

Following immunocapture of Egr-1 cross-linked to its target sites from E9 cells, the purified DNA was subjected to PCR amplification reactions for the detection of the TGF $\beta 1$ promoter. The primers used for amplification were: $5^{\prime}$ GGGCTGAAGGGACCCCCCTC-3' and 5'-TCCTCGGCGACTCCTTCCTC-3'. They represent base pairs -201 to -182 and +119 to +138 upstream and downstream, respectively, of the putative Egr-1 binding site in the TGF $\beta 1$ promoter $(10,13)$. Amplification conditions were 30 cycles of $95^{\circ} \mathrm{C}$ for $45 \mathrm{~s}$, $60^{\circ} \mathrm{C}$ for $30 \mathrm{~s}$ and $72^{\circ} \mathrm{C}$ for $45 \mathrm{~s}$.

\section{RESULTS}

\section{Immunocapture of Egr-1 from Cross-Linked Chromatin}

An outline of our DIVET method to clone Egr-1 binding sites is presented as a flow diagram in Figure 1. Previously, we have shown that $\mathrm{H} 4$ cells do not express Egr-1, even following a stimulus known to induce Egr-1 expression. Importantly, we have found that $\mathrm{H} 4$ cells do not express Egr-1 following UV irradiation, normally a strong inducer of Egr-1. However, when $\mathrm{H} 4$ cells were stably transfected with Egr-1, several clones expressing Egr-1 robustly in a constitutive manner were isolated and one of these was named E9 (9). Since these cells provide an ideal comparison for the effects of Egr-1 expression, we chose for the present study to characterize the binding of Egr-1 to its in vivo sites in E9 cells. To assess the immunocapture of Egr-1 to its binding sites, we performed Western analysis of Egr-1 following immunoprecipitation of cross-linked and digested chromatin from both $\mathrm{H} 4$ and E9 cells. Because Egr-1 can be induced and activated by a variety of extracellular stimuli, we also examined Egr-1 immunoprecipitates from cells treated with $40 \mathrm{~J} / \mathrm{m}^{2} \mathrm{UV}-\mathrm{C}(254 \mathrm{~nm})$ and incubated for $2 \mathrm{~h}$ following irradiation. Figure 2 shows the results of Egr-1 immunoprecipitation from samples of cross-linked chromatin. In $\mathrm{H} 4$ cells, there was little or no Egr-1 present in the immunoprecipitates, as we expected. In the Egr-1 constitutively expressing E9 cells, however, we successfully immunoprecipitated Egr-1 from both untreated and UV-C-treated cells. These results indicate that at least some of the Egr-1 expressed in E9 cells is bound to DNA in vivo and therefore has the potential to be functional. Furthermore, we observed that compared to untreated E9 cells, our immunoprecipitates contained considerably more Egr-1 following UV-C irradiation, which suggested that this stimulus promoted an increase in the binding of Egr-1 to its target sequences (Figure 2, compare lanes 3 and 4).

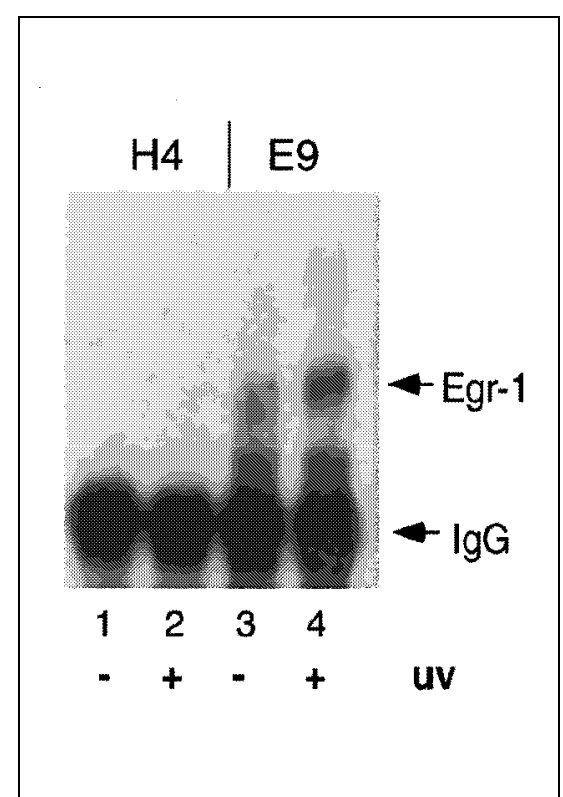

Figure 2. Egr-1 protein recovered from crosslinked chromatin. After immunoprecipitation of the chromatin fragments containing Egr-1, the DNA was digested, and the recovered protein was analyzed by SDS-PAGE and immunoblotting with the same affinity-purified rabbit antiEgr-1 IgG. Lanes 1 and 2 show that little if any Egr-1 is recovered from $\mathrm{H} 4$ cells before and after UV irradiation. Lanes 3 and 4 show that Egr- 1 recovered from E9 cells indicates a substantial increase in target frequency in UV-treated cells. 


\section{Amplification of Egr-1-Bound DNA}

To assess the capture of Egr-1bound DNA sequences, we performed linker ligation followed by PCR amplification on samples of Egr-1 immunoprecipitates from $\mathrm{H} 4$ and E9 cells. Figure 3 shows that after 20 cycles, DNA was amplified from $\mathrm{E} 9$ but not from $\mathrm{H} 4$ immunoprecipitiates. DNA fragments ranging in size from $0.5-3 \mathrm{~kb}$ were detected. This result is consistent with the presence shown by Western analysis of Egr-1 in E9 but not in $\mathrm{H} 4$ chromatin immunoprecipitates (Figure 2) and is a direct demonstration that Egr-1 is bound to DNA in these cells. Our results also suggest that following UV irradiation there may be additional sites to which Egr-1 binds, as evidenced by a different amplification profile seen in irradiated E9 cell (compare Figure 3, lanes 3 and 4).

The expression of Egr-1 in E9 cells is constitutive, and it is possible that the level is higher than one would expect after the normal induction of Egr-1. Therefore, we also tested physiologically induced Egr-1 expression in MCF7 human mammary carcinoma cells, using a two-hour exposure to tetradecanoylphorbol acetate (TPA). On a Western blot, the level of Egr-1 protein was twofold higher than that expressed in E9 cells, indicating that the method does not require high constitutive Egr-1 expression (data not shown). Also, multiple DNA fragments were captured using cross-linking of the Egr-1 to its target genes in MCF7 cells following our method. The sensitivity of the method is likely determined by the avidity of the antibody. To test the generality of the method, we also applied antibodies to c-Jun, with appropriate controls, with the result that presumptive c-Jun target genes were also captured after crosslinking (data not shown).

\section{Specific Binding of Egr-1 to Captured and Cloned Binding Sites}

To demonstrate that the DNA sequences that were amplified from E9 cells represent specific target binding sites for Egr-1, we performed gel shift assays on individual captured binding sites. Individual DNA sequences were isolated by ligating PCR products into a cloning vector and selecting single bacterial colonies after transformation, as described in the Materials and Methods section. Figure 4A presents gel shift results from three individually cloned and isolated Egr-1 binding sites from E9 cells. Purified recombinant Egr-1 bound to each of these Egr-1 binding sites. Egr-1 binding was abolished by competition using unlabeled wild-type consensus oligonucleotides but was unaffected by the mutant oligonucleotides, indicating that the binding was specific. The specific binding of Egr-1 
demonstrated here confirms that our method is effective in selecting for DNA sequences to which a transcription factor, in this case Egr-1, is directly and specifically bound in the cell.

\section{Captured Egr-1 Binding Sites Display Transcriptional Activity}

An important criterion in the characterization of in vivo Egr-1 binding sites is to determine not only the specificity of Egr-1 binding but also that the functional consequence of binding. Because Egr-1 is an immediate early transcription factor, we examined whether or not the Egr-1 binding sites that we had captured and cloned were capable of influencing the transcription of a linked reporter gene. Individual Egr-1 binding sites derived from UV-treated E9 cells were cloned into a luciferase reporter vector and transfected into $\mathrm{H} 4$ cells alone or co-transfected with an Egr-1 expression construct. Figure 4B shows

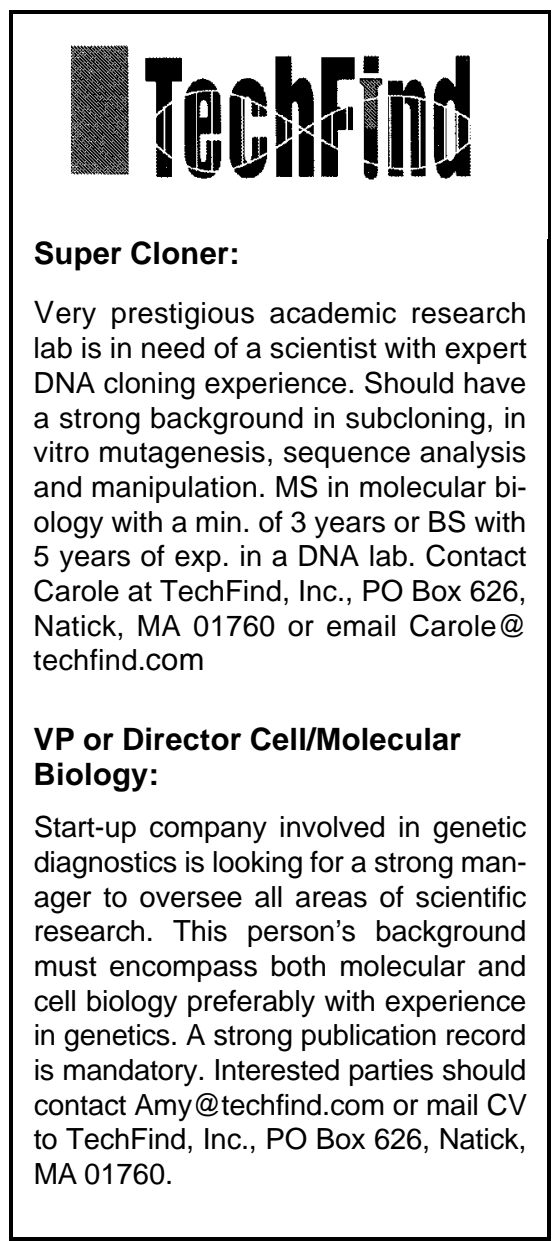

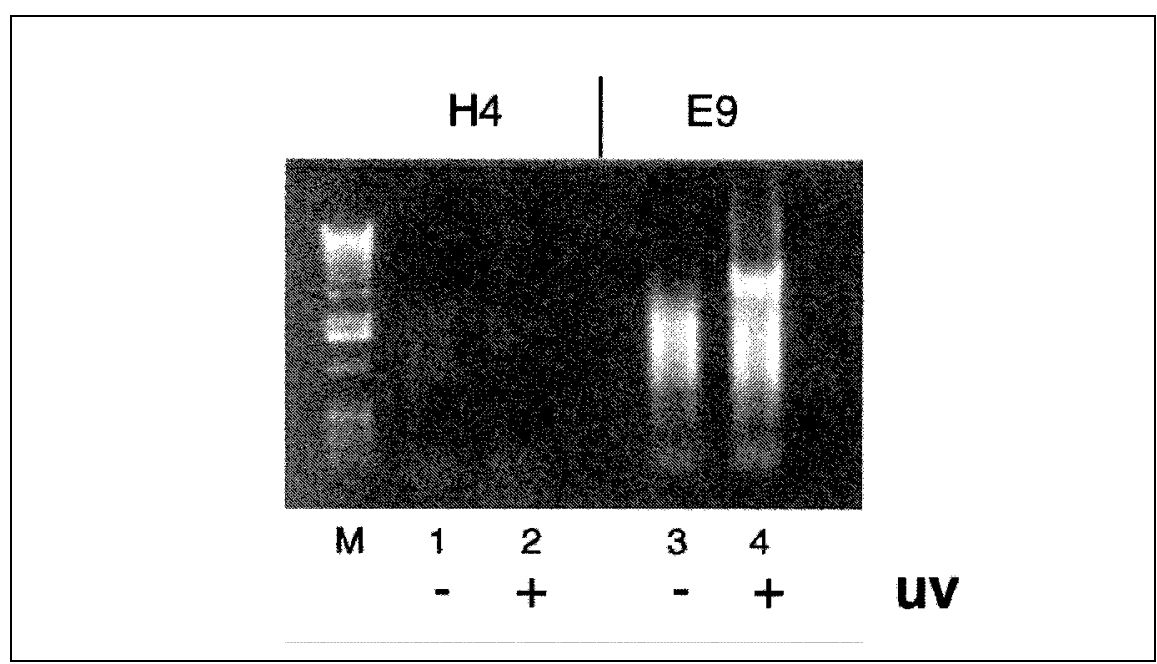

Figure 3. DNA fragments captured from HT1080 cells analyzed on an agarose gel. DNA fragments were amplified by PCR after reversal of cross-links between Egr-1 and its target DNA (see Materials and Methods for details). The lanes refer to the same cell extracts as in Figure 2.

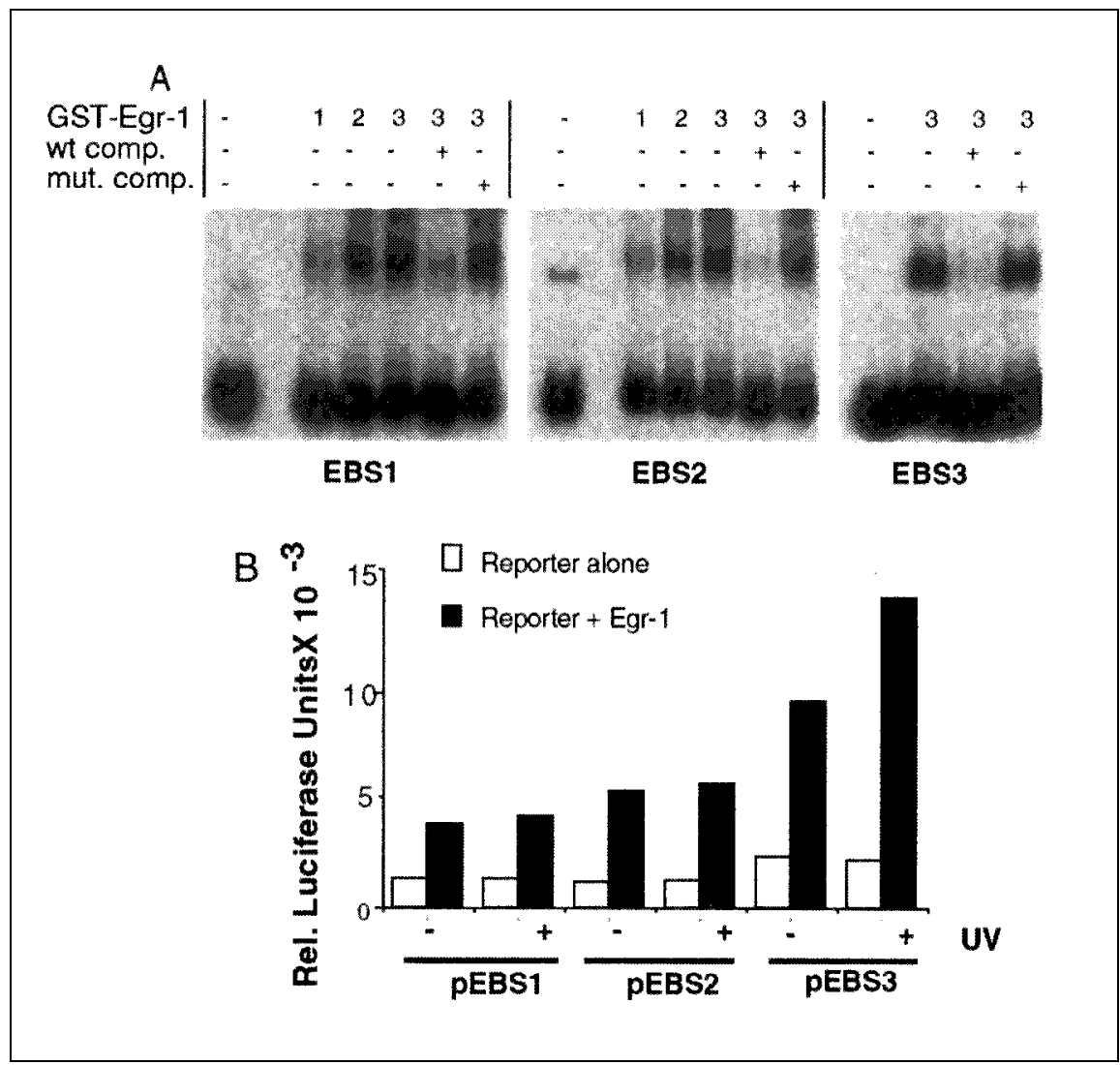

Figure 4. Egr-1 binding to and transactivation of captured DNA. (A) Gel Shift assays to show the binding specificity of captured DNA fragments. Three different DNA fragments were labeled and tested for putative Egr-1 binding sites (EBS). Recombinant GST-Egr-1 was allowed to bind as described in the Materials and Methods section. Unlabeled wild-type Egr-1 binding site oligonucleotides and mutated oligonucleotides were added to the indicated samples following Egr-1 binding as described in the Materials and Methods section. In all three cases, only the wild-type Egr-1 binding site oligonucleotides competed for the putative EBS. The concentration of Egr-1 used in gel shift studies, shown as 1, 2 and 3, corresponds to 50, 100 and $200 \mathrm{ng}$ protein, respectively. (B) Transactivation assays with a luciferase reporter gene. The same captured DNAs as in A were ligated to a minimal promoter-luciferase gene. After transient transfection into $\mathrm{H} 4$ cells, the luciferase activity of cells co-transfected with Egr-1 (black bars) was induced compared to the "empty vector" control (white bars). Only EBS3 DNA contained a UV-activated target promoter. 
the results from three Egr-1 binding sites and demonstrates that all binding sites were transcriptionally activated in the presence of Egr-1.

For Egr-1 binding sites 1 and 2, the transcriptional activation was modest and may reflect a requirement for additional cis and/or trans-acting factors for maximal activity. The transcriptional activity induced by binding sites 1 and 2 was not influenced by UV activation of Egr-1. In contrast, Egr-1 binding site 3 produced a significant trans-activation in the presence of Egr-1. Furthermore, following UV irradiation, we observed a further increase in transcriptional activity that was attributable to this binding site. This result provides a good example of the cloning of an Egr-1 binding site from irradiated cells that displays Egr-1-dependent and UV-activated transcriptional activity. From these results, it is clear that the Egr-1 binding sites captured by our method display both specificity of Egr-1 binding as well as Egr-1dependent transcriptional activity. The method described here represents a useful means by which the direct binding targets of transcription factors can be cloned, identified and characterized.

\section{Cross-Linking and Capture of Known Egr-1 Target Sites}

Twelve DNA fragments were sequenced, and searches of GenBank ${ }^{\circledR}$ and other databanks indicated that none of the sequences matched known genes, expressed sequence tags or other DNA sequences. Of the 12 sequences, three were repeats and nine were unique. To confirm that our method of isolating Egr-1 target site sequences is working effectively, we set out to determine whether or not we were able to capture a known target of Egr-1. We have reported recently that, in E9 cells, Egr-1 is a direct transactivator of the TGF $\beta 1$ gene and contributes to the growth inhibition of these cells (13). We therefore tested for the presence of the TGF $\beta 1$ promoter sequence, containing the Egr-1 binding sites, in the DNA captured from E9 cells before and after UV irradiation. Figure 5 shows the amplification of the 338-bp sequence of the TGF $\beta 1$ promoter from E9 cells. Interestingly, we found the TGF $\beta 1$ promoter sequence bound by Egr-1 in E9 cells before but not after UV irradiation. Therefore, Egr-1 may no longer transactivate the promoter fragment $2 \mathrm{~h}$ after irradiation of the cells, indicating a change in function. These results validate our method of target site cloning and demonstrate the capability of cloning Egr-1 target sequences regulating a single-copy gene. 


\section{Research Report}

\section{DISCUSSION}

Egr-1 is an immediate early gene elicited by a large range of extracellular stimuli such as growth factors. Egr-1 has multiple activities in the cell by regulating the transcription of coordinated sets of genes. One of the central themes increasingly studied with transcription factor function is the search for sites within the genome that bind these proteins to endow their regulatory function. In the case of the immediate early transcription factors, it is also fundamental to understand the mechanism of binding site selection that allows the characteristic diversity of response. To identify the complement of sites to which a transcription factor binds in vivo at any moment and under a specific set of conditions would represent a significant step toward the understanding of the activities directed by that transcription factor.

We have described here our method for cloning, which was designed to allow these questions to be answered directly. Our results have demonstrated that Egr-1 is bound to numerous sites within the genome and has the potential to influence the transcriptional activity at these sites simultaneously. We have presented results on three cloned DNA sequences. Using this method, we have

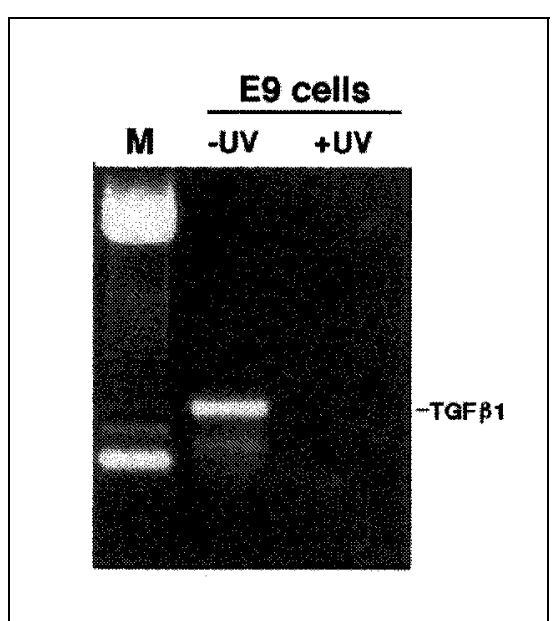

Figure 5. The capture of an authentic Egr-1regulated promoter, the TGF $\beta 1$ promoter in the DNA targets from E9 cells proves that DIVET cloning is practical. Primers that bracket the putative Egr- 1 binding site in the TGF $\beta 1$ promoter were used with the captured DNA as templates in a PCR. A band of the predicted size indicated that the TGF $\beta 1$ promoter was captured in the recovered cross-linked DNA. generated an Egr-1 binding site library that is being studied further.

It is possible that formaldehyde could cross-link protein to DNA nonspecifically, and it is likely that not all of the genuine binding sites are active in regulating transcription under all conditions. The cloning of transcription factor binding sites by this method must therefore include characterization for specificity of binding and a demonstration of functional activity associated with the binding of the transcription factor to the DNA. During the characterization of binding sites, some obvious considerations include the requirement for heterodimerization or cofactors. Dimerization has not been observed in the case of Egr-1, however. In many cases, a single transcription factor does not trans-regulate alone, but rather contributes to gene regulation as part of a complex set of protein-DNA and protein-protein interactions.

Despite these considerations, we have for the first time successfully cloned DNA sequences that both bind Egr-1 directly and influence transcription. In one case presented here, we have cloned a sequence that not only binds Egr- 1 but is also UV responsive (Figure 4B, pEBS-3). This demonstrates the possibility of identifying specific targets of transcription factors in response to a specific stimulus. In another example, we showed that TGF $\beta 1$ gene promoter sequences were captured by cross-linking to Egr-1 in E9 cells (Figure 5). This not only proves the principle of the method (because TGF $\beta 1$ is a known target of Egr-1 induction) but also is the first demonstration that Egr-1 functions in vivo by its direct binding to the TGF $\beta 1$ promoter.

Our observation that Egr-1 was not bound to the TGF $\beta 1$ promoter following UV irradiation may indicate that, following this stimulus, there is a decrease in the Egr-1-induced growth suppression in these cells. This would be consistent with our recently published results showing that following UV treatment, the expression of Egr-1 is associated with an increase in cell survival that correlates with a transient increase in the rate of cell cycle progression (4).

Moreover, we are developing a further step in this cloning method by using the longest captured DNA frag- 
ments as labeled probes to hybridize to multiplex arrays of cDNAs. Clearly, this technique has the potential for dissecting the diverse activities of transcription factors responding to a variety of signals and may reveal novel genetic targets of these factors. Moreover, the elucidation of gene clusters that are coregulated by a stimulus is a major advantage of this method.

\section{ACKNOWLEDGMENTS}

We gratefully acknowledge the support of grants from the Public Health Services, CA 67888 (E.D.A.) and CA 63783 and CA76173 (D.M.) from the National Cancer Institute and DAMD 17-99-9092 (I. de B.) from the Department of Defense.

Captured DNA sequences will be made available upon request.

\section{REFERENCES}

1.Chavrier, P., M. Zerial, P. Lemaire, J. Alemdral, R. Bravo and P. Charney. 1988. A gene encoding a protein with zinc fingers is activated during Go/G1 transition in cultured cells. EMBO J. 7:28-35.

2.Christy, B., L.F. Lau and D. Nathans. 1988. A gene activated in mouse 3T3 cells by serum growth factors encodes a protein with "zinc finger" sequence. Proc. Natl. Acad. Sci. USA 85:7857-7861.

3.de Belle, I., S. Cai and T. Kohwi-Shigematsu. 1998. The genomic sequences bound to SATB1 in vivo in T cells are tightly associated with the nuclear matrix at the base of the chromatin loops. J. Cell Biol. 141:335-348.

4.de Belle, I., R.P. Huang, Y. Fan, C. Liu, D. Mercola and E.D. Adamson. 1999. p53 and Egr-1 additively suppress transformed growth in HT1080 cells but Egr-1 counteracts p53-dependent apoptosis. Oncogene 18:3633-3642.

5.Gould, A.P., J.J. Brookman, D.I. Strutt and R.A. White. 1990. Targets of homeotic gene control in Drosophila. Nature 348:308-312.

6.Grover-Bardwick, A., E.D. Adamson and D.A. Mercola. 1994. Transformation-specific pattern of phosphorylation of c-Jun, Jun-B, Jun-D, and Egr-1 in v-sis transformed cells. Carcinogenesis 15:1667-1674.

7.Huang, R.-P. and E.D. Adamson. 1993. Characterization of the DNA-binding activity of the early growth response-1 (EGR-1) transcription factor: evidence for modulation by a redox mechanism. DNA Cell Biol. 12:265-273.

8.Huang, R.-P., T. Darland, D. Okamura, D. Mercola and E.D. Adamson. 1994. Suppression of $\mathrm{v}$-sis dependent transformation by the transcription factor, Egr-1. Oncogene 9:13671377.

9.Huang, R.-P., C.-T. Liu, Y. Fan, D.A. Mercola and E.D. Adamson. 1995. Egr-1 negatively regulates human tumor cell growth via the DNA-binding domain. Cancer Res. 55:50545062 .

10.Kim, S.J., K. Park, B.B. Rudkin, B.R. Dey, M.B. Sporn and A.B. Roberts. 1994. Nerve growth factor induces transcription of transforming growth factor-beta 1 through a specific promoter element in PC12 cells. J. Biol. Chem. 269:3739-3744.

11.Kohwi-Shigematsu, T., I. de Belle, L.A. Dickinson, S. Galande and Y. Kohwi. 1998. Identification of base-unpairing region-binding proteins and characterization of their in vivo binding sequences. Methods Cell Biol. 53:323354.

12.Lim, R.W., B.C. Varnum and H.R. Herschman. 1987. Cloning of tetradecanoyl phorbol ester-induced primary response sequences and their expression in density-arrested Swiss 3 T3 cells and a TPA non-proliferative variant. Oncogene 1:263-270.

13.Liu, C., J. Yao, I. de Belle, R.P. Huang, E.D. Adamson and D. Mercola. 1999. The transcription factor Egr-1 suppresses transformation of human fibrosarcoma HT1080 cells by coordinated induction of TGF $\beta 1$, fibronectin and plasminogen activator inhibitor-1. J. Biol. Chem. 274:4400-4411.

14.Milbrandt, J. 1986. Nerve growth factor rapidly induces c-fos in PC12 rat pheochromocytoma cells. Proc. Natl. Acad. Sci. USA 83:4789-4793.

15.Solomon, M.J. and A. Varshavsky. 1985. Formaldehyde-mediated DNA-protein crosslinking: a probe for in vivo chromatin structures. Proc. Natl. Acad. Sci. USA 82:64706474.

16.Sukhatme, V.P., X. Cao, L.C. Chang, C.H. Tsai-Morris, D. Stamenkovitch, P.C.P. Ferreira, D.R. Cohen, S.A. Edwards et al. 1988. A zinc finger-encoding gene coregulated with c-fos during growth and differentiation and after cellular depolarization. Cell 53:37-43.

Received 10 December 1999; accepted 27 March 2000.

\section{Address correspondence to:}

Dr. Ian de Belle

The Burnham Institute

10901 N. Torrey Pines Rd.

La Jolla, CA 92037, USA

e-mail:idebelle@burnham-inst.org 